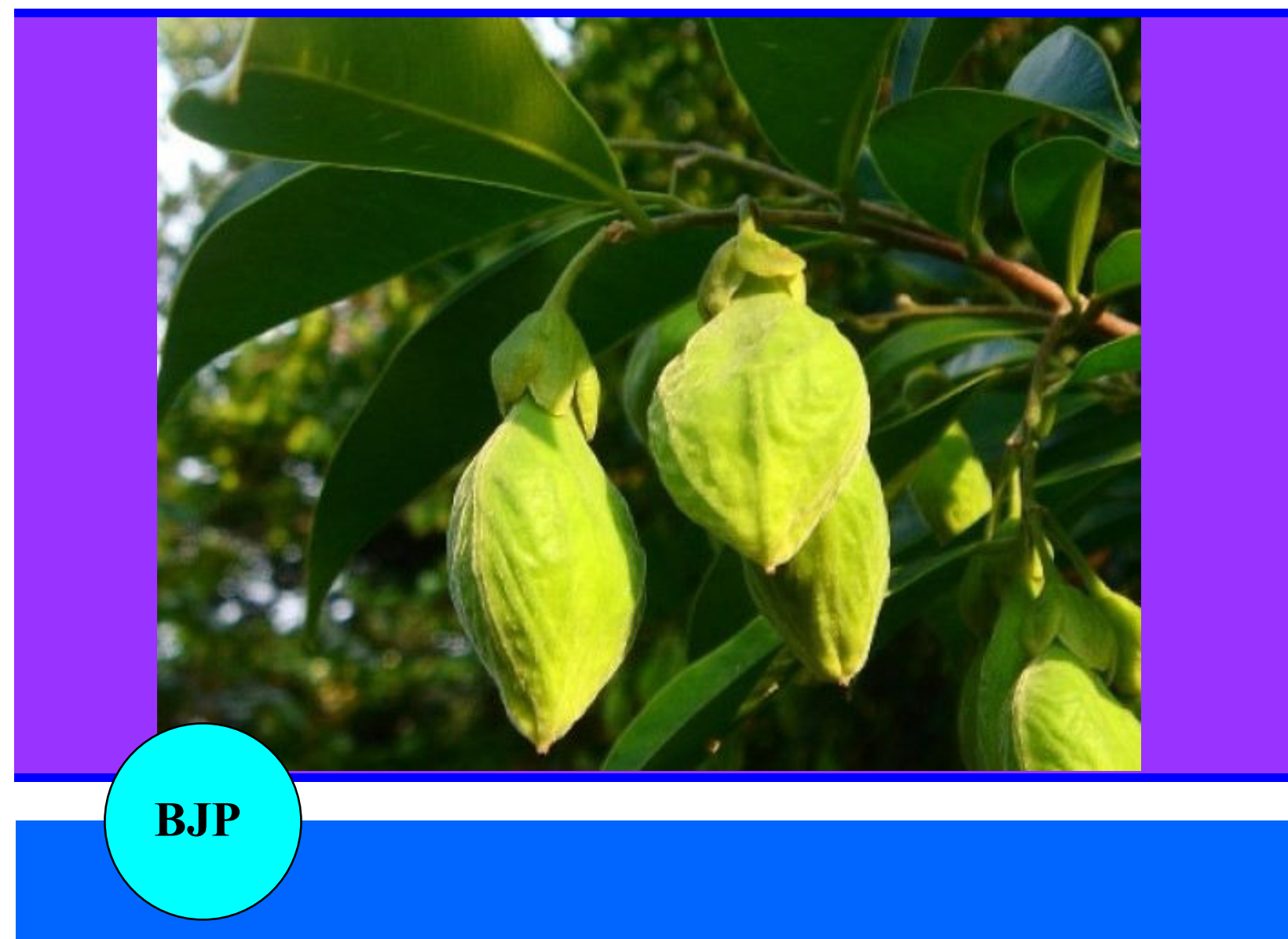

Bangladesh Journal of Pharmacology

Research Article

Inotropic and chronotropic effects of methanol extract of Aquilaria agallocha on rabbit heart 


\title{
Inotropic and chronotropic effects of methanol extract of Aquilaria agallocha on rabbit heart
}

\author{
Nawazish-I-Husain Syed', Qaisar Mahmood², Maqsood Ahmad3 and Muhammad Shoaib \\ Akhtar 2 \\ ${ }^{1}$ University College of Pharmacy, University of the Punjab, Lahore, Pakistan; ${ }^{2}$ Department of Pharmacy, University \\ of Sargodha, Sargodha, Pakistan; ${ }^{3}$ Department of Pharmacy, Bahauddin Zakariya University, Multan, Pakistan.
}

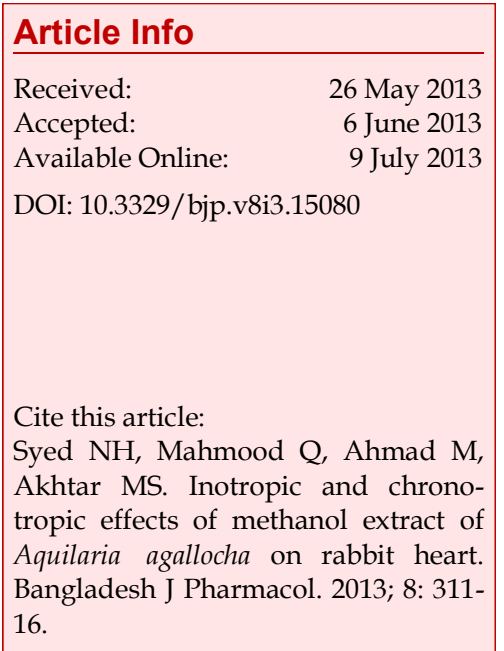

\begin{abstract}
Aquilaria agallocha Roxb. (Thymelaeceae) heartwood is used in cardiac failure; however, its cardiotonic properties are poorly understood at a pharmacological level. This study investigated methanol extract of A. agallocha for presence of glycosides and its effects on force of contraction, heart rate and coronary flow on rabbit isolated heart. Furthermore, contribution of $\beta_{1-}$ adrenoceptors and/or L-type $\mathrm{Ca}^{2+}$ channels in A. agallocha-induced cardiac effects was explored. A. agallocha extract, digoxin, verapamil and metoprolol were administered in a retrograde manner. Force of contraction and heart rate were recorded with a force transducer attached to the heart. Coronary flow was measured from collected effluent. The extract induced a significant increase in force of contraction $(p<0.001)$, decrease in heart rate $(p<0.05)$ and coronary flow $(\mathrm{p}<0.001)$. Metoprolol $(\mathrm{p}<0.01)$ and verapamil $(\mathrm{p}<0.01)$ significantly inhibited the plant extract-induced effects. Thus, A. agallocha exhibited cardiotonic effects, most likely via cardiac glycosides, involving $\beta_{1}$ - adrenoceptors and L-type $\mathrm{Ca}^{2+}$ channels.
\end{abstract}

\section{Introduction}

Cardiac glycosides remain the drugs of choice in treating congestive heart failure. However, their small therapeutic window and myriad of severe adverse effects limit their therapeutic use. To develop safe and effective agents for treating congestive heart failure, plants or their extracts have extensively been investigated for their positive inotropic and negative chronotropic effects. For example, extracts of Eremophila alternifolia R.Br. (Myoporaceae) (Pennachio et al., 1996) and Scilla maderensis Menezes (Hyacinthaceae) bulbs (Dias et al., 2000) have been reported to contain substance(s) that increase the force of contraction of the rat and frog hearts respectively. Similarly, Cecropia pachystachya Mart. (Moraceae) (Consolini et al., 2006), extract of Piper longum Linn (Piperaceae) (Lokhande et al., 2006), extract of heartwood of Pterocarpus marsupium Roxb. (Fabaceae) (Mohire et al., 2007) and aqueous extract of Berberis lyceum Royle (Berberidaceae) and berberine (Ahmad et al., 2012) have shown positive inotropic and negative chronotropic effects in rat and frog isolated heart preparations.

These agents of plant origin most likely produce their effects on heart through a variety of mechanism(s) such as inhibition of $\mathrm{Na}^{+} / \mathrm{K}^{+}$-ATPase, potasium channels, $\beta_{1-}$ adrenoceptors and voltage-gated $\mathrm{Ca}^{2+}$ channels. Previous studies have shown the cardiotonic activity of Cecropia pachystachya Mart. (Moraceae) (Consolini et al., 2006) and Cleistocalyx operculatus Roxb. (Myrtaceae) (Woo et al., 2002) in rats was due to inhibition of $\mathrm{Na}^{+}$/ $\mathrm{K}^{+}$-ATPase pump, while Crocus sativus L. (Iridaceae) has been reported to exhibit its effect via voltage-gated $\mathrm{Ca}^{2+}$ channels in isolated heart of guinea-pig (Boskabady et al., 2008). However, inotropic and chronotropic effect evoked by Piper longum Linn. (Piperaceae) (Lokhande et al., 2006), Berberis lycium and berberine (Ahmad et al., 
2012) showed $\beta_{1}$-adrenoceptor-dependent activity. Thus the plant extracts or their active principles act via a variety of mechanisms to produce inotropic or chronotropic effects.

Aquilaria agallocha Roxb. (Thymelaeaceae), also known as agar, has been used as a traditional and herbal medicine. It is widely distributed in Pakistan, India, China, Bhutan, Bengal and Tibet and reported to contain a range of active principles, including alkaloids, saponins, tannins, anthraquinones, terpenoids, fixed oils and fats (Kumar et al., 2007). Various plant extracts, including methanol extract, have also been screened for phytochemical constituents and showed the presence of glycosides in addition to other active agents (Dash et al., 2008). Keeping in view, the whole array of active constituents, A. agallocha heartwood is considered to have a broad spectrum of therapeutic effects, including anticancer (Gunasekera et al., 1981), antidepressant (Okugawa et al., 1993), antiinflammatory (Zhou et al., 2008), antihypersensitive (Kim et al., 1997) and antimicrobial (Dash et al., 2008). Patrick and Timothy (2002) have reported that this plant also possesses antioxidant principles as methanol extract of its wood has displayed strong free radical scavenging activity, which may contribute to its cardiotonic properties. Moreover, extracts from A. crassna Pierre ex lecomte (Thymelaeaceae) also showed antiischemic effects in rat ventricular myocytes (Kumphune et al., 2012) and various cardiac cell lines (Jermsri et al., 2012; Jermsri and Kumphune, 2012), which may be attributed to their anti -oxidant constituents. However, its cardiotonic effects (Miniyar et al., 2008) and use as a cardiotonic agent in folk medicines has not been well supported by studies in the isolated heart preparations using pharmacological tools. Thus, in present study, methanol extract of the plant was investigated for the presence of cardiac glycosides and further for cardiotonic properties in rabbit isolated heart preparations.

\section{Materials and Methods}

\section{Plant material}

Dried heartwood of $A$. agallocha was purchased from a local commercial herbal supplier. It was identified and authenticated by Dr. Mansoor Hameed, Associate Professor of the Department of Botany, University of Agriculture, Faisalabad, Pakistan and the specimen was assigned voucher number 10925 . It was deposited in the department's herbarium for future reference. Heartwood of A. agallocha was powdered and stored at $2-4^{\circ} \mathrm{C}$.

\section{Methanol extract}

Methanol extract was prepared by the process of cold maceration as described elsewhere (Riebliny and Walker, 2006). The extract was dried using a rotary evaporator (Stuart Bibby Steriline Ltd, UK) and the percentage yield was $15.4 \%$. The extract was stored at 2$4^{\circ} \mathrm{C}$ for pharmacological studies.

\section{Phytochemical analysis}

For determination of glycosides, Kelier-Kiliani and Salkowski's tests were performed as described (Sofowora, 1982).

\section{Kelier-Kiliani test}

Dried extract $(0.5 \mathrm{~g})$ was dissolved in $2 \mathrm{~mL}$ of glacial acetic acid containing a drop of ferric chloride and 1.5 $\mathrm{mL}$ of sulfuric acid slowly added to form a separate layer at the bottom. A brown ring at the inter-space due to the presence of deoxy sugars was characteristic of cardenolides and a pale green color in the upper layer due to the steroidal nucleus indicated the presence of glycosides (Sofowora, 1982).

\section{Salkowski's test}

Extract $(0.2 \mathrm{~g})$ was dissolved in $2 \mathrm{~mL}$ of chloroform and $2 \mathrm{~mL}$ of concentrated sulfuric acid was added. A reddish-brown layer at the interface indicated the presence of a steroidal ring which showed presence of aglycone part of glycosides (Sofowora, 1982).

\section{Langendorff studies}

Rabbits (Oryctolagus cuniculus) of either sex (1-1.5 kg) were injected with 1,000 units of heparin in the ear vein to prevent clot formation in the heart before sacrifice by cervical dislocation. The heart was removed and perfused with a Krebs-Henseleit solution composed of (mM): $\mathrm{NaCl} 118.0 ; \mathrm{KCl}$ 4.7; $\mathrm{MgCl}_{2}$ 0.5; $\mathrm{NaHCO}_{3} 25.0 ; \mathrm{NaH}_{2} \mathrm{PO}_{4}$ 1.0; Glucose 10.0; $\mathrm{CaCl}_{2} 2.2$ ( $\mathrm{pH} 7.3$ ). The solution was maintained at $37^{\circ} \mathrm{C}$, a pressure of $50-60 \mathrm{~mm} \mathrm{Hg}$ and bubbled with a $95 \% \mathrm{O}_{2}$ and $5 \% \mathrm{CO}_{2}$ gas mixture throughout the experiment. The heart was mounted intact in a Langendorff heart apparatus (120102EZ, Radnoti, USA) with a force displacement transducer (MLT0201, Panlab, Spain) connected to a Power Lab (ML865, AD Instruments, USA). All experimental procedures were carried out according to recommendations of the animal ethics and experimental committee of the Department of Pharmacy, University of Sargodah, Sargodah, Pakistan.

\section{Experimental protocol}

Drugs were administered retrogradely through a polyethylene cannula placed into aorta at the rate of 1 $\mathrm{mL} / \mathrm{min}$ for $1 \mathrm{~min}$. The effects of different concentrations of methanol extract of $A$. agallocha $(2.5,5.0,10,30$, $100,300 \mu \mathrm{g} / \mathrm{mL})$, digoxin $(10,100 \mathrm{ng} / \mathrm{mL}$ and 1, 10, 25, $50 \mu \mathrm{g} / \mathrm{mL})$, verapamil $\left(10^{-9} \mathrm{M}\right)$ and metoprolol $\left(10^{-5} \mathrm{M}\right)$ on force of contraction, heart rate and coronary flow were determined. During these experiments each heart served as its own control before administration of each drug solution or plant extract.

\section{Extract, drugs and solutions}




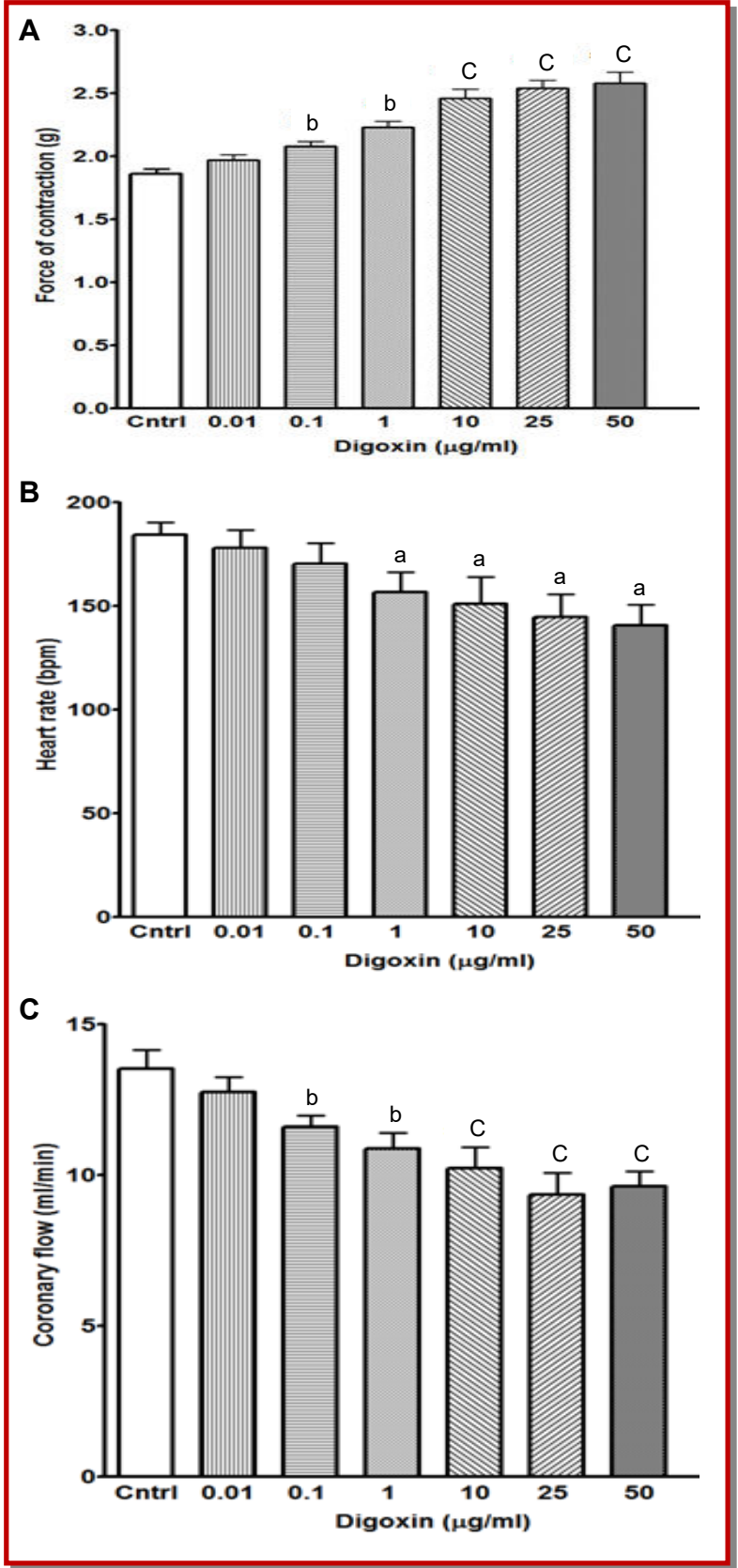

Figure 1: Effects of digoxin $(0.01-50 \mu \mathrm{g} / \mathrm{mL})$ on (A) force of contraction (g), (B) heart rate (bpm; beat/min) and (C) coronary flow $(\mathrm{mL} / \mathrm{min})$ in rabbit isolated heart. Open column shows the response in the absence of digoxin (control) while the other columns show the effects of various concentrations of the drug on above parameters of the rabbit heart. Vertical lines indicate SEM. $\mathrm{n}=6$ for each drug. ${ }^{\mathrm{a}} \mathrm{p}<0.05,{ }^{\mathrm{b}} \mathrm{p}<0.01,{ }^{\mathrm{c}} \mathrm{p}<0.00$, when compared to the control

Methanol extract of $A$. agallocha heartwood, digoxin (Glaxo SmithKline, Pakistan), verapamil (Abbott Laboratories, Turkey), metoprolol (Novartis, Pakistan) were dissolved in deionised distilled water for stock solutions and their further dilutions.

\section{Recording of data}

Force of heart contractions were recorded with a force transducer attached perpendicular to the heart by a small hook (attached to apex of the heart) and thread. The coronary flow was measured by collecting the effluent in a graduated cylinder.

\section{Statistical analysis}

Six experiments were conducted for each treatment. Data are shown as mean \pm SEM and compared using Student's paired t-test and one-way ANOVA as appropriate. Furthermore, Duncan's Multiple Range test was performed for pair-wise comparison. Probabilities of $<0.05$ were considered statistically significant.

\section{Results}

Digoxin has been used as a cardiotonic agent in treatment of congestive heart failure for many years. In the current study digoxin and methanol extract of the A. agallocha were studied in rabbit isolated heart preparations.

Kelier-Kiliani and Salkowski's tests clearly showed the presence of glycosides in the methanol extract of $A$. agallocha by color indicators for deoxy sugars and steroidal ring respectively.

Digoxin induced a significant increase in force of contraction $(p<0.001)$ (Figure 1A), significant decrease in heart rate $(p<0.05)$ (Figure $1 B)$ and a significant decrease in coronary flow $(p<0.001)$ (Figure $1 C)$ in the spontaneously beating rabbit isolated heart.

Methanol extract of A. agallocha heartwood (2.5-300 $\mu \mathrm{g} /$ $\mathrm{mL})$ significantly $(\mathrm{p}<0.001)$ increased the force of contraction of rabbit's heart in a dose-dependent manner with an $\mathrm{EC}_{50}$ values of $6.98 \pm 0.04 \mu \mathrm{g} / \mathrm{mL}$ (Figure $2 \mathrm{~A})$ and the maximum increase which was approximately $50 \%$ more than the control response was produced by $30 \mu \mathrm{g} / \mathrm{mL}$ of the extract. Increasing the concentration of the extract to $100 \mu \mathrm{g}$ and $300 \mu \mathrm{g} / \mathrm{mL}$ did not further elevate the force of contraction, but kept it steady. Similarly, a significant decrease in heart rate $(p<0.05)$ (Figure 2B) was observed with an $\mathrm{EC}_{50}$ value of $6.9 \pm 0.030 \mu \mathrm{g} / \mathrm{mL}$ on administration of the extract and the maximum decrease (34\% of the control values) was seen with $30 \mu \mathrm{g} / \mathrm{mL}$ of the plant extract. Moreover, on similar trend, addition of various concentrations of the plant extract caused a significant decrease in coronary flow $(\mathrm{p}<0.001)$ with an $\mathrm{EC}_{50}$ value of $6.4 \pm 0.07 \mu \mathrm{g} / \mathrm{mL}$ (Figure $2 \mathrm{c}$ ) and maximum response (43\% of the control response) was observed with $30 \mu \mathrm{g} / \mathrm{mL}$.

In order to investigate if the cardiac effects of methanol extract of $A$. agallocha are $\beta_{1}$-adrenergic receptor and/or voltage-gated $\mathrm{Ca}^{2+}$ channel-dependent, metoprolol (a $\beta_{1}$ -adrenergic receptor antagonist) and verapamil (L-type 


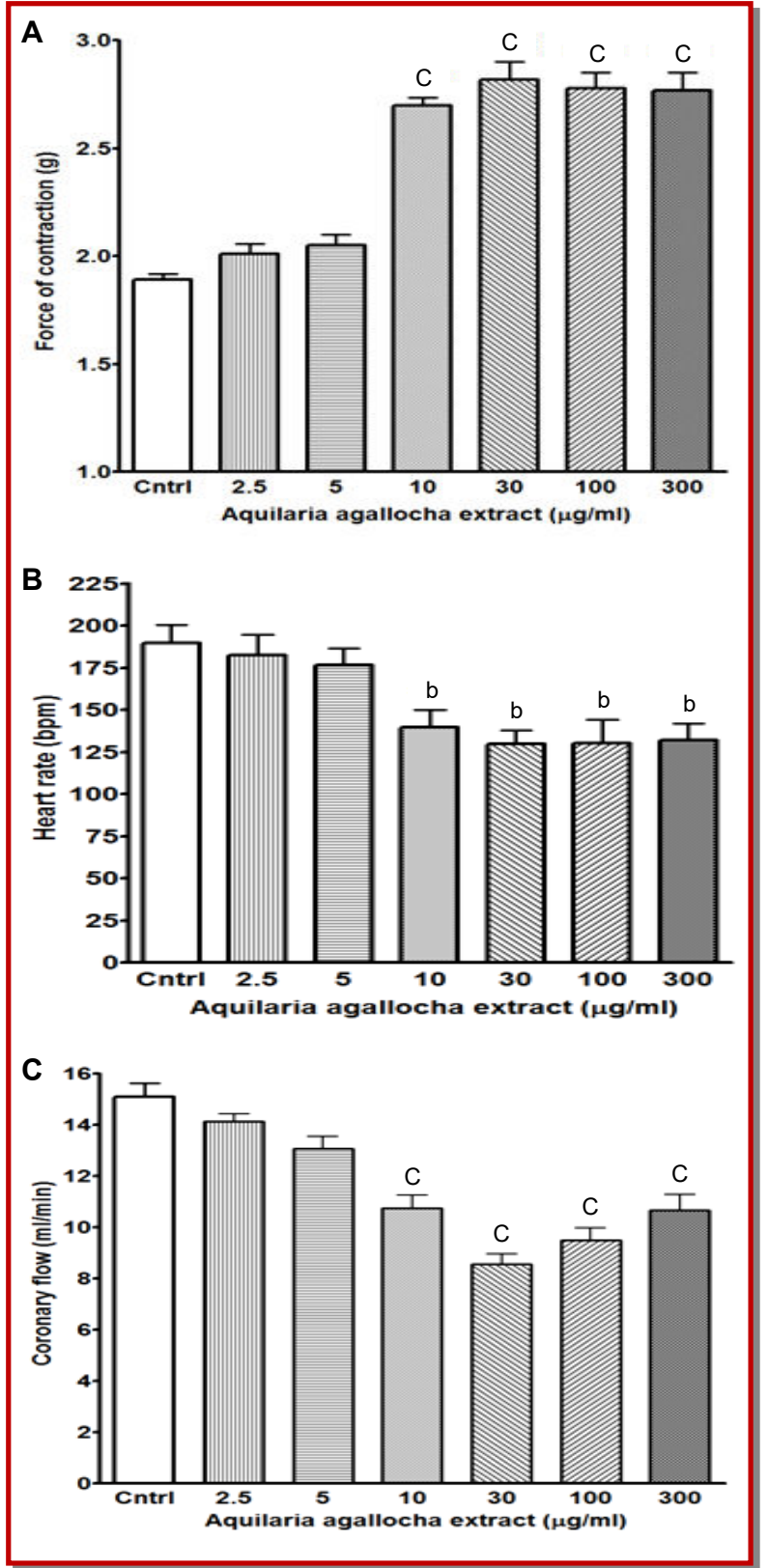

Figure 2: Effects of Aquilaria agallocha methanol extract (2.5 - 300 $\mu \mathrm{g} / \mathrm{mL}$ ) on (A) force of contraction (g), (B) heart rate (bpm; beat $/ \mathrm{min})$ and $(\mathrm{C})$ coronary flow $(\mathrm{mL} / \mathrm{min})$ in rabbit isolated heart. Open column shows the response in the absence of methanol extract (control) while the other columns show the effects of various concentrations of the drug on above parameters of the rabbit heart. Vertical lines indicate SEM. $n=6$ for each drug. a $p<0.05,{ }^{b} p<0.01, c p<0.00$, when compared to the

$\mathrm{Ca}^{2+}$ channel blocker) were applied individually before administration of the plant extract $(30 \mu \mathrm{g} / \mathrm{mL})$. The data showed that force of contraction was significantly decreased $(p<0.01)$ by metoprolol and verapamil (Figure 3A), and that addition of methanol extract of $A$. agallocha heartwood in the presence of metoprolol and verapamil did not increase force of contraction signi- ficantly (Figure 3A). Metoprolol and verapamil also significantly $(\mathrm{p}<0.05)$ decreased the heart rate and the plant extract did not cause any further decrease when administered in the presence of metoprolol and verapamil (Figure 3B). Similarly, the coronary flow in the presence of metoprolol and verapamil was significantly $(\mathrm{p}<0.05)$ decreased and the methanol extract of $A$. agallocha heartwood did not cause any further significant decrease in the presence of metoprolol and verapamil (Figure 3C).

\section{Discussion}

This study showed that methanol extract of A. agallocha contains cardiac glycosides, which is in complete accordance with the active constituents reported previously (Dash et al., 2008). The data show that there was an increase in force of contraction, a decrease in heart rate and coronary flow after administration of different doses of digoxin and methanol extract of $A$. agallocha in rabbit isolated heart. The cardiotonic effects produced by methanol extract of $A$. agallocha most likely can be attributed to glycosides present in it, which is in agreement with an earlier study showing that cardiac glycosides produce positive inotropic effects (Kitada et al., 1987). Previous studies exhibiting cardiotonic effects produced by the plants or their extracts further support our findings. For example, a study from Gilani et al. (1999) showed that $n$-butanolic fraction of Berberis aristata fruit produces a dose-dependent positive inotropic effect. Similarly, extract from rhizome of Cynodon dactylon (L.) Pers. (Poaceae) showed a significant dosedependent increase in contractile activity of frog heart (Garjani et al., 2009). Moreover, extract of Scilla maderensis bulbs has also been reported to contain substance(s) that increase the force of contraction of the frog heart (Dias et al., 2000). These studies are in agreement to the current data that plants or their extracts do exhibit carditonic effects on animal heart preparations as are shown with methanol extract of A. agallocha.

A decrease in heart rate and coronary flow after administration of the plant extract may suggest a possible explanation that it most likely occurs secondarily to an increase in the force of contraction. Administration of digoxin, a standard cardiotonic drug under similar conditions produced an increase in force of contraction, a decrease in heart rate and coronary flow in the present study. However, positive inotropic effects of the methanol extract of A. agallocha were more profound than digoxin. It indicates probably that cardiac glycosides more potent than digoxin are present in the plant extract. To the best of our information this is the first study to demonstrate the inotropic and chronotropic effects of methanol extract of A. agallocha in isolated heart preparation. 


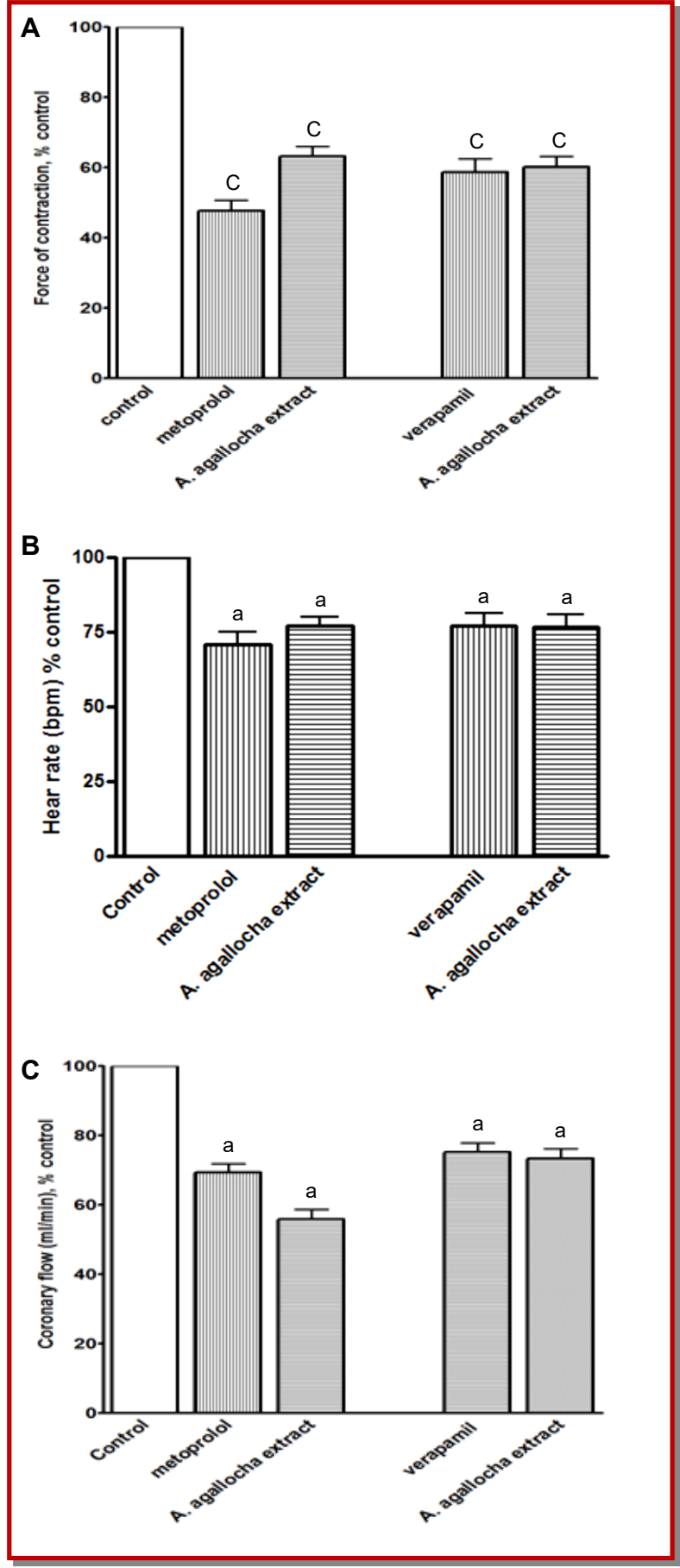

Figure 3: Postadministration effect of A. agallocha methanol extract $(30 \mu \mathrm{g} / \mathrm{mL})$ on A) force of contraction (g), (B) heart rate (bpm; beat/min) and C) coronary flow $(\mathrm{mL} / \mathrm{min})$ in rabbit isolated heart after metoprolol and verapamil. Open column shows the force of contraction \%control produced in the absence of any drug treatment while the vertical lines columns show the effects of metoprolol $(10 \mu \mathrm{M})$ and verapamil $(1 \mathrm{nM})$ and horizontal lines columns show the effects of the methanol extract $(30 \mu \mathrm{g})$ on above parameters of rabbit heart. Vertical lines indicate SEM. $n=6$ for each drug. a $p<0.05,{ }^{b} p<0.01$, $c p<0.001$, when compared to the control
The current study shows that metoprolol and verapamil decreased the force of contraction, heart rate as well as the coronary flow and post-administration of methanol extract of $A$. agallocha heartwood could not raise the force of contraction, thus indicating a role of $\beta_{1}$ adrenoceptors and L-type $\mathrm{Ca}^{2+}$ channels. Similarly post administration of plant extract in the presence of metoprolol and verapamil did not modify the heart rate and coronary flow. Our data is in line with previous studies using different plant components or plant extracts to produce inotropic and/or chronotopic effects in different animal models. For example, the cardiac effects induced by Crocus sativus were found to be L-type $\mathrm{Ca}^{2+}$ channel-dependent in isolated heart of guinea pig (Boskabady et al., 2008). However, the inotropic and chronotropic effects elicited by Piper longum (Lokhande et al., 2006), Berberis lycium and berberine (Ahmad et al., 2012) were $\beta_{1}$-adrenergic receptor-dependent. Plants or their extracts may produce their inotropic or chronotropic effects by stimulating $\beta_{1}$-adrenergic receptor and voltage-gated $\mathrm{Ca}^{2+}$ channels, either individually or together. The present findings show that both the $\beta_{1}$-adrenergic receptors and L-type $\mathrm{Ca}^{2+}$ channels contribute to the cardiac activity mediated by the plant extract.

It is concluded that methanol extract of $A$. agallocha evoke positive inotropic, negative chronotropic effects as well as decreased coronary flow, which may be due to the cardioactive glycosides or cardiac glycoside-like substance(s). The inotropic effect of the methanol extract of $A$. agallocha is blocked by metoprolol and vera -pamil thus, indicates involvement of both $\beta_{1}$-adrenergic receptors and L-type $\mathrm{Ca}^{2+}$ channels. However, further studies are suggested to fully establish mechanism of action of A. agallocha extract in eliciting the cardiac effects.

\section{References}

Ahmad M, Syed NH, Akhtar MS, Erum A, Mahmood Q, Alamgeer. Iono- and chronotropic effects of aqueous extract of Berberis lyceum Royale root bark and berberine on in stiu frog-heart preparation. Lat Am J Pharm. 2012; 31: 756-60.

Boskabady MH, Shafei MN, Shakiba A, Sefidi HS. Effect of aqueous-ethanol extract from Crocus sativus (saffron) on guinea-pig isolated heart. Phytother Res. 2008; 22: 330-34.

Consolini AE, Ragone MI, Migliori GN, Conforti P, Volonte MG. Cardiotonic and sedative effects of Cecropia pachystachya Mart. (ambay) on isolated rat hearts and conscious mice. J Ethnopharmacol. 2006; 106: 90-96.

Dash M, Patra JK, Panda PP. Phytochemical and antimicrobial screening of extracts of Aquilaria agallocha Roxb. Afr J Biotech. 2008; 7: 3531-34.

Dias C, Graca JAB, Goncalves ML. Scilla maderensis, TLC screening and positive inotropic effect of bulb extracts. J 
Ethnopharmacol. 2000; 71: 487-92.

Garjani A, Afrooziyan A, Nazemiyeh H, Najafi M, Kharazmkia A, Maleki-Dizaji N. Protective effects of hydroalcoholic extract from rhizomes of Cynodon dactylon (L.) Pers. on compensated right heart failure in rats. BMC Complement Altern Med. 2009; 9: 28.

Gilani AH, Janbaz KH, Aziz N, Herzig MJU, Kazmi MM, Choudhary MI, Herzig JW. Possible mechanism of selective inotropic activity of the $n$-butanolic fraction from Berberis aristata fruit. Gen Pharmacol. 1999; 33: 407-14.

Gunasekera SP, Kinghorn AD, Cordell GA, Farnsworth NR. Plant anti-cancer agents, XIX. Constituents of Aquilaria malaccensis. J Nat Prod. 1981; 44: 569-72.

Jermsri P, Jiraviriyakul A, Unajak S, Kumphune S. Effects of Aquilaria crassna crude extract on stimulated ischemia induced cardiac cell death. Int J Pharm Bio Sci. 2012; 3: 60413.

Jermsri P, Kumphune S. Ethylacetate extract of Aquilaria crassna preserve actin cytoskeleton on stimulated ischemia induced cardiac cell death. J Med Plants Res. 6: 2012; 405762 .

Kim YC, Lee EH, Lee YM, Kim HK, Song BK, Lee EJ, Kim HM. Effect of the aqueous extract of Aquilaria agallocha stems on the immediate hypersensitivity reactions. J Ethnopharmacol. 1997; 58: 31-38.

Kitada Y, Narimatsu A, Suzuki R, Endoh M, Taira N. Does the positive inotropic action of a novel cardiotonic agent, MCI154, involve mechanisms other than cyclic AMP? J Pharmacol Exp Ther. 1987; 243: 639-45.

Kumar AR, Subburathinam KM, Prabakar G. Phytochemical screening of selected medicinal plants asclepiadaceae family. Asian J Microbial Biotechnol Enviorn Sci. 2007; 9: 177 -80 .

Kumphune S, Jermsri P. An in vitro anti-ischemic effect of Aquilaria crassna in isolated rat ventricular myocytes subjected to stimulated ischemia. J Phytother Pharmacol. 2012; 1: 47-54.

Lokhande PD, Dhaware BS, Jagdale SC, Chabukswar AR, Atre AL. Chronotropic and inotropic effects of Piper longum Linn. Trends Appl Sci Res. 2006; 1: 634-39.

Miniyar BP, Chitre TS, Karve SS, Deuskar HJ, Jain KS. Antioxidant activity of ethylacetate extract of Aquilaria agellocha on nitrite-induced methemoglobin formation. Int J Green Pharm. 2008; 1: 43-44.

Mohire NC, Salunkhe VR, Bhise SB, Yadav AV. Cardiotonic activity of aqueous extract of heartwood of Pterocarpus marsupium. Indian J Exp Biol. 2007; 45: 532-37.

Okugawa, H, Ueda R, Matsumoto K, Kawanishi K, Katao A. Effects of agarwood extracts on the central nervous systems in mice. Planta Med. 1993; 59: 32-36.

Patrick LO, Timothy J. Anti-oxidants in medicines and spices as cardioprotective agents in Tibetan highlanders. Pharm Biol. 2002; 40: 346-57.

Pennacchio M, Syah YM, Ghisalberti EL, Alexander E. Cardioactive compounds from Eremophila species. J Ethnopharmacol. 1996; 53: 21-27.

Riebliny PW, Walker GC. Extractions and extractives. In: Remington's Pharmaceutical Sciences. Maryland, USA, Lippincott Williams \& Wilkins, 2006.

Sofowora A. Medicinal plants and traditional medicine in Africa. Ibadan Nigeria, Spectrum Books, 1982, p 6, 154.

Woo AYH, Waye MMY, Kwan HS, Chan MC, Chau CF, Cheng CHK. Inhibition of ATPases by Cleistocalyx operculatus: A possible mechanism for the cardiotonic actions of the herb. Vasc Pharmacol. 2002; 38: 163-68.

Zhou M, Wang H, Suolangjiba, Kou J, Yu B. Antinociceptive and anti-inflammatory activities of Aquilaria sinensis (Lour.) Gilg. leaves extract. J Ethnopharmacol. 2008; 117: 345-50. 